\title{
O Behaviorismo Radical e a Interdisciplinaridade: Possibilidade de uma Nova Síntese?
}

\author{
Evenice Santos Chaves ${ }^{1}$ \\ Olavo de Faria Galvão \\ Universidade Federal do Pará
}

\begin{abstract}
Resumo
A ciência psicológica é historicamente atravessada por conflitos inter teóricos, decorrentes de enfoques diferenciados com relação a conhecimentos produzidos pelos fundamentos epistemológicos, teóricos e metodológicos, pelas hegemonias e pelo próprio recorte sobre o objeto em estudo, realizado por pesquisadores. Contemporaneamente, a epistemologia da complexidade chama atenção para a incompletude de cada tipo de conhecimento científico produzido, o que tem gerado ressonâncias nos fazeres de pesquisadores e propiciado novos diálogos entre perspectivas diversificadas em cada enfoque, ou entre enfoques. O presente artigo propõe diálogos entre aspectos do behaviorismo radical e do construtivismo crítico formal, ressaltando relações de complementaridade, a partir da unidade de contrários, que podem implicar numa nova síntese: uma teoria geral do significado. Nessa direção enfocar-se-á a proposição de nova síntese, a qual configura uma compreensão teórica sobre o desenvolvimento do significado e reinterpreta o papel do reforçamento na construção e ampliação dos significados. Palavras-chave: Interdisciplinaridade; complexidade; complementaridade; teoria geral do significado.
\end{abstract}

\section{Radical Behaviorism and Interdisciplinary Research: Would a New Synthesis be Possible in Psychology?}

\begin{abstract}
Psychology as science is historically engaged in theoretical disputes resulting from divergent viewpoints concerning the nature of knowledge generated by different epistemological, theoretical and methodological approaches, and by the particular divisions in the subject matter made by the researchers themselves. At the present time, epistemology of the complexity calls attention to the incompleteness, characteristic of scientific knowledge, that in turn affects the conduct of researchers, creating conditions for new dialogues between differing perspectives within and between disciplines. This article proposes a renewal of the dialogue between radical behaviorism and formal critical constructivism that, by emphasizing complementary relationships and opposing polarized thinking which has permeated these disciplines, may result in a new synthesis or new general theory of meaning. A new synthesis between the two approaches would reformulate the understanding of meaning development and the role of the reinforcement in the construction and enhancement of meaning.

Keywords: Interdisciplinarity; complexity; complementarity; general theory of meaning.
\end{abstract}

Uma dimensão constitutiva da produção do conhecimento científico éo limite inerente à própria captação de um dado fenômeno em estudo. Uma via explicativa desse limite diz respeito ao recorte efetuado na realidade pelo pesquisador, que, visando o estudo de aspectos específicos de um objeto, retira o fenômeno do seu curso contínuo e o transforma num evento discreto.

O pesquisador, ao realizar essa operação, está cônscio da problemática relativa a tal forma de operatividade. Além disso, o seu olhar, sempre construído e reconstruído na inserção social, traz a marca dos seus viéses, do seu modo de ser no mundo social e das suas crenças científicas.

De acordo com Ferreira, Calvoso e Gonzales (2002), o investigador, enquanto observador do fenômeno em estudo, constitui o eixo configurador do conhecimento, do qual é participante ativo, pois o que produz decorre da sua experiência estruturada nas interpretações que confere ao objeto em estudo, sempre vinculado a um contexto e a uma história.

Entretanto, os referidos autores salientam que tal propriedade não significa sustentar que na produção do conhecimento científico tudo vale (Ferreira \& cols., 2002, p. 247), mas que ela relaciona-se a contingências presentes no momento da construção científica.

\footnotetext{
${ }^{1}$ Endereço para correspondência: Prof. Dr. Olavo de Faria Galvão, Trav Castelo Branco, 1116, 1004, 66063 000, Belém, PA. Fax: (91) 2111783. E-mail. ofg@cpgp.ufpa.br
}

Uma implicação decorrente é a de que diferentes autores elaboram múltiplas e parciais orientações teóricas, assim como explicitam posições referentes a diálogos, nem sempre amistosos, entre os enfoques teóricos, visando, geralmente, cotejar diferenças, identificar complementaridades ou perspectivas irreconciliáveis.

No interjogo, ressaltamos o papel da epistemologia da complexidade que, ao desenvolver um conjunto de reflexões críticas e sugerir caminhos para os fazeres científicos, colabora no processo construtivo de problematizar fundamentos e conhecimentos produzidos.

Sem apologias ou antipatias a enfoques, porém perseguindo o ideal da democratização na ciência e da saudável interlocução entre diferentes orientações teóricas, toma-se como de grande importância a noção de complexidade inerente a cada objeto em estudo, a qual demarca a incompletude de conhecimentos produzidos por diferentes pesquisadores e a necessária relação de complementaridade entre diversos campos do conhecimento científico (Morin, 1982/1999).

No âmbito da Psicologia há autores corroborando as afirmações acima descritas, como, por exemplo: Donahoe e Palmer (1994), que ao discorrerem sobre as origens do comportamento aprendido argumentam sobre a sua complexidade, defendendo a postura da relação complementar entre diferentes áreas do conhecimento; Galvão (1999), que, ao analisar as inter-relações entre a análise experimental do comportamento e a neurociência, cita que uma serve de complemento à outra, Tourinho, Teixeira e Maciel (2000) que, ao 
situarem a questão de enfoques irreconciliáveis, indicam uma demarcação de fronteira entre a análise do comportamento e a fisiologia, ressaltando, porém, a relação de complementaridade entre elas, Chaves (2000), que, ao abordar o enfoque transdisciplinar na construção do conhecimento sobre um objeto em estudo, defende a necessidade do investigador debruçar-se sobre diferentes perspectivas, formuladas em diversos campos científicos, acerca de um dado objeto de investigação científica.

Assim, construir conhecimentos sobre um fenômeno requer a compreensão da incompletude daqueles já produzidos, e, em contrapartida, a necessidade do diálogo, da complementação ou da reconstrução descritivo-compreensiva e explanatória, a partir das contribuições de pesquisadores orientados por diferentes enfoques.

A Psicologia parece priorizar a análise das diferenças entre as orientações teóricas, o que reduz a exploração das similaridades, das contradições e de relações complementares que possam ser identificadas.

Considerando-se diferenças e complementaridades entre dois enfoques, o presente trabalho objetiva explicitar a concepção de materialismo em dois enfoques da Psicologia, o behaviorismo radical e o construtivismo crítico formal, assim como descrever relações intra e entre enfoques, visando uma compreensão e explanação mais abrangente do papel do processo de reforçamento na construção do significado, pelos seres humanos.

Os conteúdos serão focalizados nos seguintes temas: da noção de entidade à concepção materialista do ser humano; a unidade de contrários e a possibilidade de uma nova síntese; a proposição de uma nova síntese; considerações finais.

\section{Da Noção de Entidade à Concepção Materialista do Ser Humano}

Sampson (2001) menciona que a noção de entidade foi incorporada ao ator social objeto de estudo da Psicologia, conformando a concepção de indivíduo não relacional, desprovido de cultura, auto-suficiente, a-histórico, imaculado e purificado. Ressalta que tal visão de ser humano, no plano histórico, foi formulada pelo iluminismo, e, também, dominou a Psicologia construída no século XX.

Assevera que no mundo ocidental o esclarecimento, ou iluminismo, ordenou-se em oposição à organização social e às tradições da religião pertinentes àquela época. Buscando superálas, continua Sampson (2001), o iluminismo elaborou uma concepção de ser humano abstrato, puro, de caráter universalista, regido apenas pelas leis da natureza, que transcendiam o lugar (cultura) e o tempo (história).

Sampson (2001) ainda descreve que, na ótica do iluminismo, princípios semelhantes deveriam ser descobertos e tomados como verdadeiros para a compreensão dos fenômenos humanos. Tal fundamento gerou a concepção de entidade e um sistema de pensamento congruente, incorporado pelas Ciências Humanas. Especificamente, cita que as bases da cultura e da história foram desconsideradas pela Psicologia, fazendo emergir construções científicas que advogavam apenas a classificação e a ordenação das pessoas em função das suas aproximações ou distanciamentos de uma assim denominada normalidade.

Contudo, destacamos que esse quadro não corresponde a toda a Psicologia construída no século XX, pois diferentes filosofias embasaram a desconstrução da entidade e propuseram formas de inserir o ser psicológico no contexto social, como veremos a seguir.

O behaviorismo radical, como arcabouço filosófico, opôs-se e opõe-se à noção de entidade e conseqüentes sistemas classificatórios oriundos de grande parte da Psicologia do século XX.

Pereira (1997) retoma dois pontos enfatizados na obra realizada por Skinner: a concepção materialista da natureza humana e o entrelaçamento do materialismo à natureza contingente das realizações humanas.

Souza (2000), ao realizar uma análise histórica do conceito de contingência, também evidencia a natureza materialista dessa perspectiva científica, ao relatar que tanto o ambiente natural, quanto $\mathrm{o}$ ambiente construído produzem contingências que podem produzir modificações no ambiente, se o organismo se comporta de um dado modo.

Para explicitar a base material do comportamento humano, Skinner (1984a) formulou, a partir do princípio da seleção natural, um enfoque sobre a seleção dos comportamentos pelas conseqüências: a seleção por conseqüências filogenéticas, relacionadas à preservação da espécie; a seleção ontogenética, que, através de contingências, atua sobre o indivíduo quando ele interage com o ambiente, e a seleção cultural das práticas sociais, que opera garantindo a sobrevivência dos grupos.

Chiesa (1994) salienta que no behaviorismo radical o comportamento das pessoas configura uma unidade constituída por uma composição hereditária, uma história de reforçamento, considerada como experiência de vida, e pelas relações com o ambiente.

A causalidade no behaviorismo radical fundamenta-se no enfoque da seleção pelas conseqüências. Conforme Chiesa (1994), as explicações causais decorrem das relações interativas bidirecionais entre a pessoa e o ambiente. A referida autora explicita que as relações decorrentes das interações entre o comportamento da pessoa e os eventos do ambiente são causadas pelas condições produtoras de contingências, as quais operam em um lugar específico, e pelas conseqüências do comportamento.

O behaviorismo radical, ainda que vinculado ao rompimento com a tradição religiosa, portanto ao iluminismo, sustenta, conforme Pereira (1997) a negação de qualquer benefício transcendental ao humano, resultado de uma insistência em evidenciar como estamos atrelados aos mesmos embaraços evolutivos que as demais espécies (p. 37).

Para corroborar as formulações realizadas por Pereira (1997) e Souza (2000), acerca da base materialista e contingente da natureza humana, enfatizamos a afirmação elaborada por Skinner (1984a), de que a história do comportamento humano teve início, presumivelmente, no extraordinário momento (p. 477) da existência de uma célula e do seu poder de auto-reprodução.

Ademais, Skinner (1984a) ressalta que o envolvimento do ser vivo com o ambiente impõe limites às funções biológicas, pois o bom funcionamento do comportamento requer condições 
específicas, possibilitadas pela evolução, através dos processos de condicionamento operante e reflexo, os quais permitem ao organismo individual adquirir comportamentos consonantes como o novo ambiente.

As interpretações e os fundamentos explicitados pelos três autores acima citados possibilitam afirmar que: a) para o behaviorismo radical, o comportamento constrói-se e reconstróise a partir das relações estabelecidas entre um organismo vivo e o ambiente, o que confere um caráter materialista ao enfoque; b) neste, a concepção de movimento e mudança no organismo individual tem lugar, devido a determinadas condições e à operatividade dos processos de condicionamento; e, c) o organismo individual é valorizado devido a unidade entre o ambiente social, físico e o interno, estruturadores de contingências que proporcionam uma articulação individual, expressa nos repertórios comportamentais constitutivos da pessoalidade.

O construtivismo crítico formal, outro enfoque filosófico da Psicologia, fundamenta-se na noção de que a realidade é socialmente construída a partir das relações sociais, o que confere uma base materialista às produções científicas orientadas por esse enfoque: a psicologia narrativa, constitutiva da vertente histórico-cultural, cujos conceitos de significado e sentido são centrais nas construções teóricas (Brockeimer, 2000; Bruner, 1990/1997; Lyddon, 1995/1997), as quais têm produzido conhecimentos científicos na Psicologia Clínica, Psicologia Social e na Psicologia do Desenvolvimento.

A metáfora-raiz que fundamenta o construtivismo crítico formal é aquela elaborada por Pepper em 1942, a qual, segundo Lyddon (1995/1997) circunscreve a noção de hipóteses de mundo: uma concepção acerca de como ele funciona, que possibilita a operatividade do sujeito através de pressupostos tácitos, advindos dos entendimentos construídos no cotidiano e articulados a partir dos conhecimentos circulantes.

Tal metáfora-raiz é o contextualismo que, segundo Lyddon (1995/1997), ancora-se na historicidade e se expressa através da operatividade de um evento num dado contexto. Prossegue, afirmando que a mudança e a novidade são dimensões constitutivas do contextualismo, de onde as compreensões humanas formuladas emergem, de forma integrada, numa síntese elaboradora da unidade decorrente de especificidades constitutivas de um ato em seu contexto.

Rey (1997) assinala que para o construtivismo, incluindo o crítico formal, as pessoas constroem a realidade, o que significa a inserção do sujeito no processo de elaboração do conhecimento. A visibilidade do caráter interacionista do enfoque é expressa pelo autor, ao ressaltar que o conhecimento resulta da ação do sujeito sobre a realidade, sendo determinado pelas propriedades da realidade e do sujeito, que caracteriza-se pelo seu permanente esforço em construir significados. Isso, para Rey, propicia uma relação contínua entre a experiência e sua significação.

O enfoque na experiência humana toma o processo autobiográfico como fonte de informações que geram dados a partir de re-construções narrativas (Brockeimer, 2000; Bruner,1990/1997; Lyddon, 1995/1997).

Brockeimer (2000) cita que a narrativa é uma atividade humana construída na interação social e esse processo explicitase no discurso, oral ou escrito, onde as pessoas ordenam as suas experiências, interpretando-as e reconstruindo-as em consonância com as convenções culturais.

Brockeimer (2000), no entanto, chama atenção para o fato de que as re-construções sobre os eventos passados e, conseqüentemente, os conteúdos das histórias que os seres humanos elaboram sobre as suas experiências, não representam conhecimentos armazenados na memória sobre as próprias vivências, lembrados de forma coerente, exata e linear aos acontecimentos já vividos.

Desse modo, o construtivismo crítico formal contrapõe-se à teoria do processamento de informações e, conforme Brockeimer (2000), ao reconstruir aspectos da própria experiência através das narrativas, a pessoa o faz de acordo com o contexto da cada elaboração, com as convenções da sua cultura e com as especificidades do grupo cultural onde está inserida. O referido pesquisador enfatiza que de tais condicionantes emerge o significado, ou seja, a significação social dos conteúdos verbais expressos, e o sentido, ou seja, a significação pessoal que cada pessoa atribui a acontecimentos já vividos ou presenciados.

Os condicionantes acima descritos formam a base da noção de causalidade: a ação humana é propiciada por inter-relações entre o contexto, os condicionantes que operam numa dada situação, o significado e o sentido que as pessoas atribuem às suas experiências ou ações.

Para Rey (1997), das inter-relações entre as dimensões do mundo social, da experiência e da ação do sujeito decorre a subjetividade social, que impõe as lógicas e os sistemas individuais, propiciadores de conflitos. Conforme o referido autor, tais inter-relações impossibilitam a compreensão do individual desvinculada do social, pois pessoa e objeto integramse como unidade no processo de construção do conhecimento, o qual, por sua vez, configura perspectivas que o sujeito elege privilegiar mais ou menos temporalmente.

A partir da fundamentação de que as construções humanas são possíveis graças à ação contextualizada, Lyddon (1995/1997) afirma que o construtivismo crítico formal concebe que a realidade, tanto social, quanto pessoal, é ativa e opera como um fluxo contínuo de eventos.

Sintetizando, podemos afirmar que esse enfoque evidencia uma concepção materialista do ser humano enquanto ser sóciopsicológico; a materialidade do mundo social enquanto dimensão constitutiva e constituinte da unidade ação-reflexão-ação, objetivada na atividade humana, nos discursos e nos significados elaborados por diferentes interlocutores; uma concepção de realidade e de pessoa enquanto movimento produtor de mudanças no tempo e espaço, dado os diferentes contextos culturais onde o ser humano atua.

Do exposto até então, podemos assegurar que os dois enfoques abordados defendem a materialidade como fundamento 
da ação humana: o behaviorismo radical a explica através do processo de seleção dos comportamentos contingentes, enquanto o construtivismo crítico formal através do contextualismo, do processo de construção dos significados sociais e dos sentidos.

Os dois enfoques abordados consideram o ser humano como sujeito socialmente construído, como agentes que atuam sobre o meio, e, também, privilegiam a os condicionantes sociais como constituinte e constitutivo das ações humanas.

A Unidade de Contrários e a Possibilidade de uma Nova Síntese

Historicamente, as diferentes orientações teóricas em Psicologia têm produzido e mantido relações de oposição que, em muitos momentos, são beligerantes e afastam a possibilidade do diálogo entre as diferenças.

Essa situação, além de contribuir para emperrar o avanço científico e maior relacionamento entre a pesquisa básica e aquela advinda do cotidiano, tem proporcionado hegemonias efêmeras.

DeGrandpre (2000), reportando-se à Psicologia Operante skinneriana, afirma que os princípios oriundos de tal enfoque têm influenciado a filosofia e a ciência, a pesquisa básica experimental, a denominada ciência aplicada, a intervenção clínica, a intervenção organizacional, a intervenção vinculada ao abuso de substâncias e a psicofarmacologia. Contudo, relata que a análise experimental do comportamento representa uma força marginalizada na Psicologia científica contemporânea.

DeGrandpre (2000) coloca que tal marginalização advém, em grande parte, da análise experimental do comportamento recusar-se a elaborar orientações teóricas acerca dos processos mentais, nas quais eles são considerados como construtos explanatórios ou como causalidade vinculada à experiência e às ações humanas.

A compreensão da recusa enfatizada por DeGrandpre pode ser ampliada à luz de afirmações explicitadas por Wilson e Hayes (2000) de que apesar de Skinner ter abordado, no plano filosófico, a possibilidade da análise científica dos eventos privados desde 1945, ao longo da segunda metade do século XX o tema foi excluído das pesquisas realizadas pelos analistas do comportamento. Os referidos autores interpretam que isso decorreu da refutação metodológica à introspecção, feita por Watson em 1924, através do argumento de que os eventos privados não geravam acordos entre observadores.

Wilson e Hayes (2000), ainda descrevem como razão de ordem pragmática para tal exclusão, a afirmação de Skinner, em 1953, de que os eventos privados eram legitimamente científicos, porém não era necessária a sua compreensão científica.

Essas interpretações de Wilson e Hayes (2000) são, entretanto, passíveis de contra-argumentação. Moxley (1998), por exemplo, cita que há muitas incompreensões e interpretações confusas em análises realizadas sobre o trabalho de Skinner, as quais decorrem do fato de Skinner ter modificado formulações teóricas ao longo de sua vida como cientista, sem, no entanto, justificar com argumentos as razões para tais mudanças. Segundo o citado autor, isso gera interpretações confusas.
Com relação à recusa da introspecção por Watson e conseqüente recusa dos eventos não observáveis enquanto objeto de estudo da Psicologia, devido à impossibilidade de seu estudo pelo método empírico-experimental (Watson, 1925), não podemos afirmar que Skinner, no conjunto da sua obra, tenha se posicionado da mesma maneira.

Segundo Tourinho e cols. (2000) o empreendimento realizado por Watson para superar a idéia de mediadores mentais para o comportamento (p. 428), foi a sua substituição pela noção de mediadores fisiológicos, passíveis de serem estudados através do método empírico-experimental.

Para Tourinho e cols. (2000), Skinner, em 1963, interpretou que Watson não produziu uma sólida compreensão sobre o fenômeno comportamental e, ainda, gerou discussões relativas aos eventos internos ao organismo.

Skinner (1963/1975) deslocou a discussão da causalidade interna para o ambiente, ao afirmar que Nenbuma descrição do intercâmbio entre o organismo e o meio ambiente estará completa enquanto não incluir a ação do ambiente sobre o organismo depois da emissão da resposta (p. 10).

Moxley (1998) relata que Skinner, em 1963, não colocou impedimentos para a consideração dos eventos mentais ou privados na explicação do comportamento, pois Skinner afirmou que processos ou entidades que tenham poder explanatório não podem ser descartados, sejam eles subjetivos ou mentais. Moxley ainda argumentou que as objeções de Skinner foram dirigidas à concepção dos eventos privados como a origem do comportamento humano.

De fato, Skinner (1963/1975) cita que inventaram processos e mecanismos interiores para explicar o comportamento. Para o autor, naquele contexto, quando um organismo comportava-se de modo previsto com relação a estímulos que não estavam fisicamente presentes na situação, os pesquisadores interpretavam que aquele organismo estava respondendo a cópias dos referidos estímulos, armazenadas na memória. Ainda segundo Skinner, a Psicologia do estímulo, resposta das décadas de 30 e 40 do século XIX explicava a causalidade do comportamento recorrendo aos processos mentais que prometera eliminar.

Do exposto até então observamos que a oposição de Skinner, naquela época, foi dirigida ao enfoque do processamento de informações. Skinner (1984b) deixa claro que uma ciência do comportamento adequada deve considerar eventos que tomam lugar dentro da pele do organismo, não como mediadores fisiológicos do comportamento, mas como parte do próprio comportamento, ressaltando que a pele não é importante como um limite (p. 617).

A este respeito, Moxley (1998) cita que Skinner, em 1989, voltou a afirmar que aquilo que acontece dentro do corpo não é o início, a origem do comportamento humano. Moxley, no mesmo trabalho, relata que em 1984, Skinner delimitou o ambiente externo como aquele que fornece as causas iniciais para o comportamento humano, as quais não podem ser separadas da história passada.

Em suma, Skinner construiu proposições teóricas que descartam a noção dos processos mentais como causa principal do comportamento, porém, como salientam Tourinho e cols. (2000) 
não negou a existência de um mundo interno (p. 431). Moxley (1998), a partir de sua interpretação de aspectos da obra de Skinner, cita que para esse autor os eventos privados podem ser causas, mas não causas iniciais (p. 81).

Desse modo, podemos relativizar a afirmação de Skinner em 1953, citada por Wilson e Hayes (2000), de que os eventos privados constituem uma categoria científica, porém não necessária à sua compreensão científica.

Por outro lado, situar como desnecessária a investigação sobre os eventos privados significa apenas uma afirmação de Skinner, explicitada em um momento das suas construções teóricas, porém não mantida ao longo do seu enfoque sobre os eventos privados.

A referida afirmação também não significa uma desautorização de Skinner para a realização de investigações sobre os eventos privados, o que, na verdade, não compete a nenhum acadêmico. Desse modo, hipotetizamos que o abandono de investigações sobre os eventos privados não é uma questão skinneriana, mas decorre da escolha de caminhos por outros pesquisadores que trabalham com o enfoque do behaviorismo radical.

Demo (1995) refere-se a essa problemática através do que denomina de argumento da autoridade: uma afirmação, calcada apenas em verbalizações de uma autoridade científica circula, não é questionada e influencia no tipo de conhecimento científico que vem a ser produzido. Isso parece compatibilizar a afirmação que Skinner fez em 1953 sobre a investigação dos eventos privados, com a aceitação inquestionável daquela afirmação, por muitos pesquisadores.

DeGrandpre (2000) chama atenção para o posicionamento clássico do behaviorismo radical frente ao estudo científico dos processos mentais, afirmando que ele restringe a abrangência da aplicação da Psicologia Operante, cria demandas para outros enfoques e uma condição marginal, obscurecendo a sua contribuição ao processo contemporâneo de construção de uma Psicologia de natureza prática.

Ainda mencionamos, no âmbito dos enfoques em Psicologia, as escassas reflexões sobre aincompletude de cada um frente à compreensão e explanação de fenômenos psicológicos. Quando realizados, geralmente observamos uma conduta reflexiva fundada na lógica da negação, que, provavelmente, impede o desenvolvimento de orientações teóricas com maior escopo, quando há compatibilidades e relações de complementaridade entre diferentes enfoques.

Tomar a incompletude inerente ao conhecimento produzido em cada área da Psicologia pode gerar a possibilidade de identificação de contradições e da unidade de contrários. Como a ciência constitui-se enquanto produção social historicamente situada, As realidades sociais não são apenas complexas; são, sobretudo, complexidades polarizadas. São campos magnetizados, onde qualquer presença provoca ação e reação, e mesmo a ausência é maneira de polarizar (Demo, 1995, p. 97).

Orientado pela lógica da unidade de contrários, DeGrandpre (2000) aborda o processo de reforçamento como uma possibilidade de articulação entre conhecimentos produzidos pela pesquisa básica na Análise Experimental do Comportamento e pela Psicologia do Significado.

Aquestão decorrenteé: será possível a emergência de uma construção científica orientada pela complementaridade entre diferentes enfoques?

No contexto acadêmico de produção do conhecimento científico isso já demonstrou ser possível, pois a partir da interdisciplinaridade surgiu o campo dos Estudos Culturais, que começou a ser elaborado em 1970, na Inglaterra (Guareschi \& Bruschi, 2003). Então, a interdisciplinaridade, fundamentada em um nexo entre enfoques, também poderá ser viável na Psicologia e contribuir para a produção de novos conhecimentos científicos.

Cada enfoque de um fenômeno psicológico constitui uma síntese e, conforme Demo (1995), na totalidade dialética a realidade social produz o seu contrário, a antítese, a qual, segundo o autor, é algo negativo, pois diz respeito ao que falta. O estudioso, entretanto, assegura que a radicalização dos contrários provoca transformações, e, como conseqüência, uma nova síntese.

Ressaltamos que, evidentemente, a nova síntese é qualitativamente diferente da inicial, faz surgir o novo, completando, desse modo, o ciclo polarizado da unidade de contrários. A formulação emergente avança e, ao mesmo tempo, gera novas unidades de contrários, garantindo a qualidade dinâmica e transformadora dos diferentes movimentos, no caso daqueles constitutivos da produção científica.

DeGrandpre (2000) defende a possibilidade de uma ciência básica do significado, a partir do reforçamento como um processo básico estabelecido pela Análise Experimental do Comportamento e do conceito de significado, central na Psicologia Histórico-Cultural.

DeGrandpre (2000) identifica as antíteses pertinentes aos conhecimentos produzidos pelos dois enfoques, e, posteriormente, elabora aspectos que podemos ressaltar como constitutivos de uma nova síntese na compreensão, explanação e teorização sobre o papel do processo de reforçamento no desenvolvimento dos significados.

Enquanto antítese dos princípios da Psicologia Operante, DeGrandpre (2000) relata que os mesmos são limitados enquanto provedores de uma completa orientação teórica sobre a experiência humana e a ação psicológica. Defende, então, a necessidade de exploração das implicações de princípios operantes para uma ciência psicológica do significado.

No tocante à Psicologia do Significado DeGrandpre (2000) ressalta que ela tem desempenhado um relevante papel na demonstração da natureza social dos seres humanos, do significado como constitutivo do self e dos objetos, porém, no presente, há escassas evidências que permitem compreender o desenvolvimento da construção dos significados pelos seres humanos. Observamos que tal questão forma uma antítese.

DeGrandpre (2000), partindo do entendimento de que Skinner, já em 1935, admitiu a existência de processos psicológicos básicos, afirma que os processos genéricos já estão descritos com acuidade pela Psicologia Operante. Contudo, o referido pesquisador sustenta que é necessário o estabelecimento de conexões entre princípios operantes e da Psicologia do Significado, visando a possibilidade da construção de uma ciência básica do significado.

\section{A Proposição de uma Nova Síntese}

Conforme DeGrandpre (2000), a aquisição de significados é possível através da experiência da pessoa no mundo, a qual tem uma qualidade contingente, possibilitada por estruturas de superfície e por estruturas extensivas.

Psicologia: Reflexão e Crítica, 2005, 18(3), pp.308-314 
As estruturas de superfície referem-se às esferas da atividade onde a pessoa tem uma experiência limitada ou participa de modo desmotivado. As estruturas extensivas referem-se às experiências prolongadas, geradoras de capacidades comportamentais, além de outras experiências e compreensões qualitativamente diferentes. Por serem socialmente construídas, ligadas a situações e práticas sociais, estão permanentemente se modificando.

Para DeGrandpre (2000), dada sua qualidade social, o significado permanece no mundo, é função do que foi historicamente vivenciado pelo sujeito, possibilitando, assim, a dinâmica experiencial da mudança e da disrupção. Isso, de acordo com o autor, relativiza o significado e o torna dialético: a pessoa atua no mundo e esse responde, estabelecendo-se aí um processo interativo que cria significados para episódios comportamentais, numa temporalidade distendida.

O citado pesquisador acrescenta que quanto mais experiências a pessoa acumula, mais provável é a sua familiaridade com a situação e, nesse processo, o significado modifica-se através de diferentes interpretações, na temporalidade da ação.

De acordo com DeGrandpre (2000), como conseqüência, os significados organizam o senso de realidade através do movimento da pessoa nos contextos familiares; orientam as ações no mundo e a produção de outros significados; antecipam, de modo consciente, outros significados, que são, ao mesmo tempo, definidos pela experiência passada.

DeGrandpre (2000) ainda aborda o episódio comportamental, ressaltando que ele configura-se num momento experiencial único, composto por quatro dimensões: os aspectos definidos pela experiência passada como familiares na situação presente; os aspectos singulares públicos e privados do contexto no qual um ato particular toma lugar; o próprio ato; os conseqüentes eventos estímulos, temporalmente contíguos ao próprio ato.

Acerca do desenvolvimento psicológico, DeGrandpre (2000) assegura que a contradição é a pré-condição para a sua ocorrência, pois as expectativas e as ações produzem conseqüências inesperadas, enquanto que as experiências desconhecidas e discrepantes são produtoras de suposições sobre o que ocorreu, gerando a transformação do significado do episódio comportamental. Tal processo, para o autor, viabiliza entender como o comportamento complexo e o significado emergem num plano coletivo e contingente, nas interações dialéticas entre o mundo físico, o mundo social e o pessoal.

Após essa organização teórica sobre a construção de significados, DeGrandpre (2000) apropria-se do processo de reforçamento como via descritiva e explanatória para a construção dialética do significado.

O referido investigador relata que, correntemente, o reforçamento tem sido interpretado na Psicologia, como uma operação na qual a probabilidade ou força do comportamento é aumentada on diminuida pelas suas consequiencias, isto é: por reforçadores ou punição (p. 726). Todavia, assegura que tal interpretação obscurece o relevante papel do reforçamento na construção do significado.

Partindo de afirmações realizadas em 1953 e em 1981 por Skinner e daquela de Donahoe e Palmer em 1994, de que as conseqüências do comportamento produzem alterações nas relações entre estímulos e respostas, DeGrandpre, (2000) cita que um reforçador ou agente punitivo não afeta o comportamento precedente, porém modifica o significado do estímulo contextual saliente, oportunizando momento e significação às ações futuras, ou seja: o reforçamento especifica um dado significado, o qual orienta o comportamento e dinamiza a experiência.

DeGrandpre (2000) destaca que no contexto ecológico, propiciador da emergência de novos significados, o modo como a pessoa experiencia as conseqüências de suas ações dá direção às futuras ações. As ações possibilitam novas experiências, sustentando ou não a significação já existente acerca do mundo físico, social, dos objetos e das pessoas. Fundamenta essa teorização na colocação realizada por Donahoe e Palmer em 1994 (citado em DeGrandpre, 2000), de que os efeitos das conseqüências sobre o comportamento ocorrem devido à alteração do significado futuro para um contexto antecedente.

A configuração teórica do processo de construção do significado elaborada por DeGrandpre (2000), a partir do que considera como complementaridade entre a Psicologia Operante e a Psicologia do Significado, é um passo inicial na direção de uma teoria geral do significado. Essa poderá permitir a compreensão e explanação de especificidades do ser humano contextualmente situado, enquanto sujeito ativo nas suas próprias experiências, condicionadas pelas diferentes situações, as quais the permitem atuar no mundo social e fenomenal.

Sumarizando, enfatizamos que sua proposição introduz o sujeito como agente ativo no próprio processo de construção, ampliação e modificação de significados durante o seu curso de vida e introduz na Psicologia Operante uma forma de interpretação qualitativa que poderá permitir, a partir de relações de contingência, a explanação de como repertórios humanos, sociais e fenomenais são ampliados, a partir da influência de novos significados emergentes nos contextos onde $\mathrm{o}$ ato humano toma lugar.

\section{Considerações Finais}

Assim como falar que o processo permanente de construção do significado depende, em parte, de experiências e de significados anteriormente construídos, o avanço do conhecimento científico na Psicologia sobre processos psicológicos depende, em parte, dos conhecimentos antecedentes produzidos por diferentes enfoques, das subseqüentes crises e marginalizações, que, ao invés de serem concebidas como nefastas, podem ser compreendidas como salutares para a superação de limites.

As diferenças, conforme aponta Demo (1995), proporcionam diálogos no campo dos conflitos e é nesse campo que as compreensões e incompreensões integram o processo de comunicação, em cujas entranhas está situado o próprio diálogo, que, para o referido pesquisador, só é possível quando existem vozes contrárias, porque quando as falas são idênticas tem-se o monólogo.

Tomando por suposto que o ato de dialogar com diferentes enfoques escancara as diferenças e os vazios teórico-metodológicos, 
o presente estudo buscou um diálogo entre duas orientações teóricas contemporâneas da Psicologia, apontando a concepção materialista de ser humano como algo comum entre eles.

A configuração teórica sobre a construção do significado e o papel do reforçamento nesse processo realizada por DeGrandpre (2000) representa uma nova síntese, organizada a partir de conhecimentos prévios produzidos e de vazios teóricos pertinentes à Psicologia Operante e à Psicologia do Significado. O empreendimento desse pesquisador ainda denota um processo social de construção do conhecimento na Psicologia que busca superar oposições e hegemonias temporalmente situadas e historicamente arraigadas.

DeGrandpre (2000) fundamentando-se em orientações teóricas e contradições existentes nas produções advindas do behaviorismo radical e do construtivismo crítico formal, realiza uma nova articulação teórica que poderá desembocar em pesquisas inovadoras, na direção de uma teoria geral do significado, situada no tempo, na cultura e em contextos de desenvolvimento humano.

A partir de DeGrandpre (2000) propomos o desafio para a construção de uma teoria geral do significado que incorpore o macro, o meso e o micro contexto, o que pode ser uma possibilidade ou um limite no que concerne às construções teóricas mais abrangentes. Apenas a pesquisa e a construção teórica responderão a essa proposta.

\section{Referências}

Brockeimer, J. (2000). Autobigraphical time. Narrative Inquiry, 10, 51-73.

Bruner,J. (1997). Atos de significação. Porto Alegre: Artes Médicas. (Original publicado em 1990)

Chaves, A. M. (2000). O fenômeno psicológico como objeto de estudo transdisciplinar. Psicologia: Reflexão e Crítica, 13, 159-165.

Chiesa, M. (1994). Radical behaviorism: The philosophy and the science. Boston: Authors Cooperative.
DeGrandpre, R. J. (2000). A science of meaning: Can behaviorism bring meaning to psychological science? American Psychologist, 55, 721-739.

Demo, P. (1995). Metodologia científica em ciências sociais. São Paulo: Atlas.

Donahoe, J. W. \& Palmer, D. C. (1994). Learning and complex behavior: Boston, MA: Allyn \& Bacon.

Ferreira, R. F., Calvoso, G. G. \& Gonzales, C. B. L. (2002). Caminhos da pesquisa e a contemporaneidade. Psicologia: Reflexão e Crítica, 15, 243-250.

Galvão, O. F. (1999). O reforçamento na biologia evolucionária atual. Revista Brasileira de Terapia Comportamental e Cognitiva, 1, 49-56.

Guareschi, N. M. F. \& M. E. Bruschi, M. E. (Orgs.) (2003). Psicologia social nos estudos culturais: Perspectivas e desafios para um nova psicologia social. Petrópolis, RJ: Vozes.

Rey, F. G. (1997). Epistemología cualitativa y subjetividad. São Paulo: Educ.

Lyddon, M. J. (1997). Formas e facetas da psicologia construtivista. Em R. A. Niemeyer \& M. J. Mahoney (Orgs.), Construtivismo em psicoterapia (pp. 6078). Porto Alegre: Artes Médicas. (Original publicado em 1995)

Morin, E. (1999). Ciência com consciência. Rio de Janeiro: BCD. (Original publicado em 1982)

Moxley, R. A. (1998). Why Skinner is difficult. The Behavior Analyst, 21, 73-91.

Pereira, A. M. (1997). Definições do humano em Skinner e Rorty. Interfaces, 1,37-40.

Sampson, E. E. (2001). To think differently- The acting ensemble: A new unity for psychology inquiry. The International Journal of Critical Psychology, 1, 47-61.

Skinner, B. F. (1975). Contingências do reforço. São Paulo: Abril Cultural. (Original publicado em 1963)

Skinner, B. F. (1984a). Selection by consequences. Behavioral and Brain Sciences, 7, 477510.

Skinner, B. F. (1984b). Behaviorism at fifty. Behavioral and Brain Sciences, 7, 615-667.

Souza, D. G. (2000). O conceito de contingência: Um enfoque histórico. Temas em Psicologia da SBP, 8, 125-136.

Tourinho, E. Z., Teixeira, E. R. \& Maciel, J. L. (2000). Fronteiras entre Análise do Comportamento e fisiologia: Skinner e a temática dos eventos privados. Psicologia: Reflexão e Crítica, 13, 425-434.

Watson, J. B. (1925). Behaviorism. New York, NY: People's.

Wilson, K. G. \& Hayes, S. C. (2000). Why it is crucial to understand thinking and feeling: An analysis and application to drug abuse. The Behavior Analyst, 23, 2543.

Recebido: 25/05/2004 Aceite final: 11/09/2004

Sobre os autores

Evenice Santos Chaves é Doutoranda do Programa de Pós Graduação em Teoria e Pesquisa do Comportamento na Universidade Federal do Pará. É bolsista da CAPES.

Olavo de Faria Galvão é Professor Adjunto IV no Departamento de Psicologia Experimental da Universidade Federal do Pará. É Pesquisador 1C CNPQ. 